Case Report

\title{
A Case of Chondrosarcoma Arising in the Temporomandibular Joint
}

\author{
Tsutomu Nomura, Tadaharu Kobayashi, Susumu Shingaki, and Chikara Saito \\ Division of Reconstructive Surgery for Oral and Maxillofacial Region, Department of Tissue Regeneration and Reconstruction, \\ Course for Oral Life Science, Niigata University Graduate School of Medical and Dental Sciences, Gakkocho-dori 2-5274, \\ Chuo-ku, Niigata 951-8514, Japan \\ Correspondence should be addressed to Tsutomu Nomura; t-nomura@bc5.so-net.ne.jp
}

Received 6 September 2014; Revised 28 December 2014; Accepted 28 December 2014

Academic Editor: David W. Eisele

Copyright (c) 2015 Tsutomu Nomura et al. This is an open access article distributed under the Creative Commons Attribution License, which permits unrestricted use, distribution, and reproduction in any medium, provided the original work is properly cited.

Chondrosarcoma is a malignant tumor originating in cartilaginous cells. And there are only few reports of the case of chondrosarcoma in temporomandibular joint. We discuss a case of chondrosarcoma in temporomandibular joint in a 28 -yearold man. Tumor was in contact with the dura, but en bloc resection was performed. After surgical resection of the tumor, face defect was reconstructed by rectus abdominis-free flap. And there is no recurrence after ten years from the resection.

\section{Introduction}

Chondrosarcoma is a malignant tumor originating in cartilaginous cells and retaining this nature throughout its evolution. Next to osteogenic sarcoma, chondrosarcoma is the most common bone tumor $[1,2]$.

It is rare in the head and neck area especially in the mandible. And there are only few cases of chondrosarcoma in temporomandibular joint. Despite the malignant tumor, chondrosarcoma cases have a long duration from onset to first visit to the hospital [3]. In this case, the duration was ten years and it was one of the longest cases in the collected literatures [4-19].

And treatment of the tumor in the temporomandibular joint is very difficult, because of involvement of facial nerve, parotid gland, and cranial base.

This report describes the details of the case with diagnosis and treatment.

\section{Case Presentation}

A 28-year-old man noticed a swelling of the left preauricular region ten years before presenting at our hospital and simultaneously had a mouth opening limitation.
Although a mouth opening limitation was decreased gradually, he noticed a spontaneous pain of the same region one year before presenting. He visited our clinic, and the patient denied any history of general systemic diseases. The size of preauricular swelling was $40 \mathrm{~mm}$ in diameter, but there was no facial paralysis. The lesion was elastic, hard, and tender and was covered with normal skin. There were no abnormal findings about cervical lymph nodes (Figure 1).

The mouth opening was $23 \mathrm{~mm}$ between upper and lower incisors, and there was a restriction of both lateral and anterior movements.

Panoramic X-ray showed a bone resorption from left fossa to condyle (Figure 2).

Computed tomography (CT) scan showed a mass arising from the temporomandibular joint and size was $40 \mathrm{~mm}$ in length, $50 \mathrm{~mm}$ in width, and $30 \mathrm{~mm}$ in height. Enhancement of tumor was low (Figure 3(a)). In superior area, infratemporal fossa was eroded and tumor invaded middle cranial fossa. The mass was seen in cranial area, but invasion of dura was not obvious (Figure 3(b)).

Magnetic resonance imaging (MRI) showed that tumor was expanding close to dura (Figure 3(c)).

To make differential diagnosis, the biopsy was done with preauricular incision. Under the zygomatic arch, the 


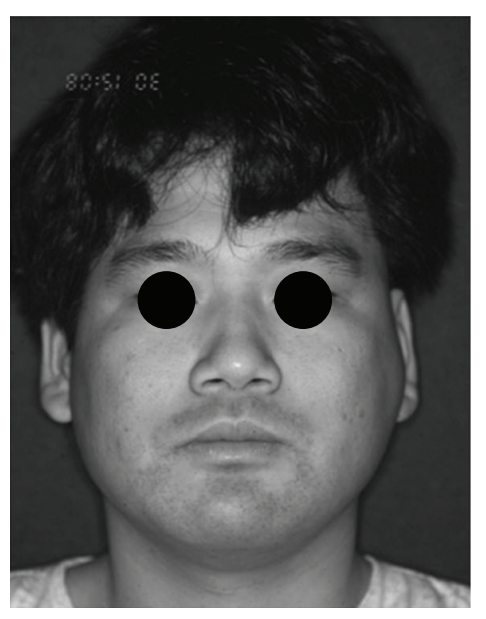

FIGURE 1: Left side preauricular swelling on presentation.

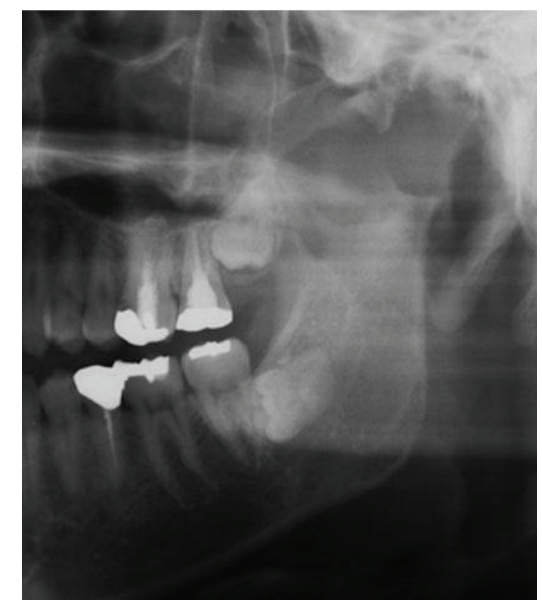

FIGURE 2: Bone resorption from left fossa to condyle in panorama radiograph.

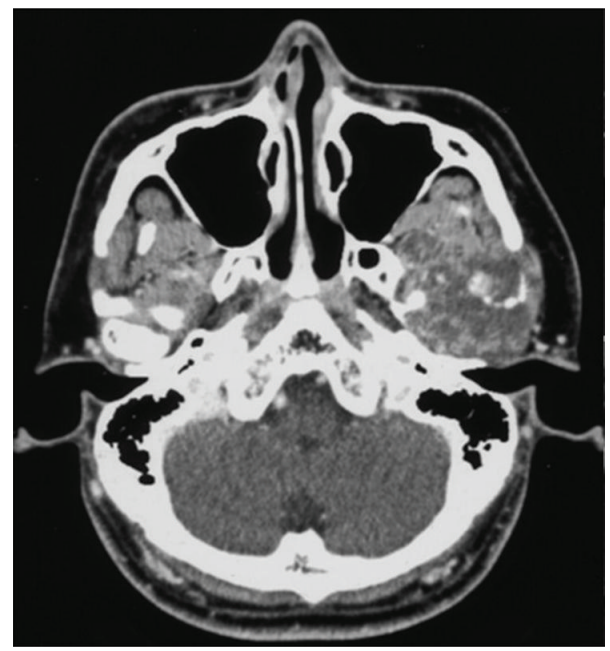

(a)

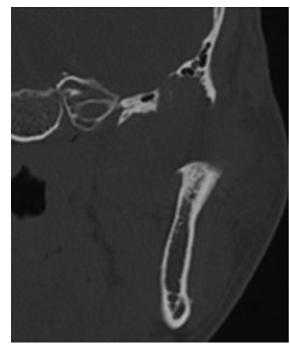

(b)

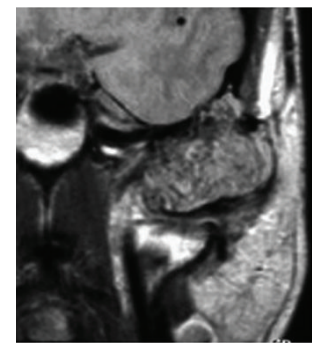

(c)

FIGURE 3: (a) Low-enhanced tumor around the condyle head in contrast-enhanced CT scan; (b) infratemporal fossa erosion and middle cranial invasion of tumor in coronal view of CT scan; (c) tumor expansion close to dura in enhanced MRI. 
tumor was exposed by collagen capsule incision. The tumor seemed gelatinous. In histological findings, heterogeneous sized tumor cells were embedded in chondrocyte lacuna in the mucinous or chondroid stroma. Although the mitotic figures were not seen, polymorphism of the tumor cells was significant. The diagnosis was chondrosarcoma.

The mass was wide excised and removed from the adjacent structure (temporal process of zygoma, zygomatic process of temporal bone, ramus, and parotid gland) and removed in a single block.

The base of the cranial bone had two bone defects in $5 \mathrm{~mm}$ size, but there was no invasion of dura, and the resection of dura was not performed.

In the resected specimen, the disk and lower synovial membrane was seen in intact, and the tumor invaded left parotid gland.

Microscopic examination showed that the tumor was composed of a diffuse proliferation of atypical chondrocytic cells in myxoid or chondroid matrix where granular calcified materials were scattered (Figure 4(a)). The tumor cells showed cellular pleomorphism with bizarre appearance of nuclei. The mitosis was seen in some area (Figure 4(b)). Histological diagnosis was low grade (Grade 1) chondrosarcoma.

For the left buccal defect, reconstruction of the left buccal area was done with abdominus cutaneous flap one year after tumor resection (Figure 5). Only soft tissue was reconstructed because of no complaint of mastication.

The recurrence was not seen after ten years from the tumor resection (Figure 6).

\section{Discussion}

Chondrosarcoma is a malignant tumor originating in cartilaginous cells and retaining this nature throughout its evolution. Excluding the report with some missing clinical data, there are only seventeen reports of the cases of chondrosarcoma in temporomandibular joint [4-19] in English literature.

About the age, the mean age of the temporomandibular joint (TMJ) chondrosarcoma is 48 years, and Murayama et al. [20] reported that the mean age of mandible chondrosarcoma is 38 years and Saito et al. [3] reported that it is 41.6 years. The age is higher in TMJ chondrosarcoma group.

And about sex distribution, although Murayama et al. [20] and Saito et al. [3] reported that sex distribution is even in chondrosarcoma in the head and neck area, female is more predominant than male (12 versus 5) in chondrosarcoma in TMJ area.

All these characters of chondrosarcoma in temporomandibular joint are different from chondrosarcoma of head and neck area.

The most major symptom is swelling, followed by pain. Trismus was found in half of the cases. In cases presenting with a preauricular mass, intra-articular tumor can be misdiagnosed as other benign or malignant diseases, such as osteochondromatosis, osteoarthritis, rheumatoid arthritis, avascular necrosis, and condylar fractures. And chondrosarcoma is sometimes misrecognized with temporomandibular disorder. This could be one of the reasons for diagnostic delay.
And some cases had no complaint of pain like our case, and those cases had tendency to have long symptom duration.

And the average of symptom duration of TMJ group is 24 months. It was longer than 8 months in mandible tumor by Murayama et al. [20], 12 months by Saito et al. [3], and 14 months by Weiss Jr. and Bennett [21]. From these data, chondrosarcoma in TMJ seems to have a slow growth character.

To make a correct diagnosis panorama X-ray, CT, and MRI are effective.

Panorama X-ray showed the apparent resorption of condyle head. These findings suggested the tumor in the condyle but not adequate extension area. CT scan showed the invasion of middle cranial fossa and MRI showed tumor expansion close to dura. Performing both CT scan and MRI leads to accurate diagnosis and to making adequate treatment plan.

Cranial invasion was reported by Morris et al. [10], Nitzan et al. [12], and Mostafapour and Futran [15]. We had asked neurosurgeon to back up for cranial surgery. But fortunately we did not need cranial surgery. In case of dura invasion, cooperation with neurosurgeon is imperative.

From Garzino-Demo et al's review [17] and our case (Table 1), the symptom duration of the 8 cases that had condyle resorption is $24,8,24,72,120,3,12$, and 120 months. These periods were longer than the duration of the cases without condyle resorption.

From this point, destructive potential of chondrosarcoma is almost the same, but the duration could influence the extent of bone resorption.

In terms of diagnosis, fine needle biopsy is not enough for chondrosarcoma from collected literature $[15,18]$. And open biopsy is definite to get final diagnosis. Histologically, our case showed Grade I and Nortjé et al. [8], Morris et al. [10], Nitzan et al. [12], Sesenna et al. [13], Garzino-Demo et al. [17], and González-Pérez et al. [18] reported low grade (Grade I) chondrosarcoma. Other reports had no grading information. Our case had a good follow-up course, and all other collected cases have also good prognosis. Murayama et al. [20] reported that 8 of 20 patients died 5 months to 6 years after the primary treatment. Although Evans et al. [22] reported that pathological grade was useful prognostic factor, Saito et al. [3] reported that the grade was not related to the prognosis.

We could not conclude the reason of good prognosis of the chondrosarcoma in TMJ comparing with chondrosarcoma in other head and neck areas, but it might be related to the high rate of Grade I in TMJ chondrosarcoma.

About the treatment, all cases had surgery. As Weiss Jr. and Bennett [21] reported that chemotherapy and radiotherapy are ineffective in chondrosarcoma, wide resection of the tumor is key to the success. Chemotherapy and radiotherapy should be considered in unresected case or positive margin case.

Next to the successful tumor resection, esthetic appearance is very important in head and neck area. Nortjé et al. [8] used sternocleidomastoid muscle (SCM) flap and Nitzan et al. [12] used the temporalis muscle rotation flap for reconstruction. 


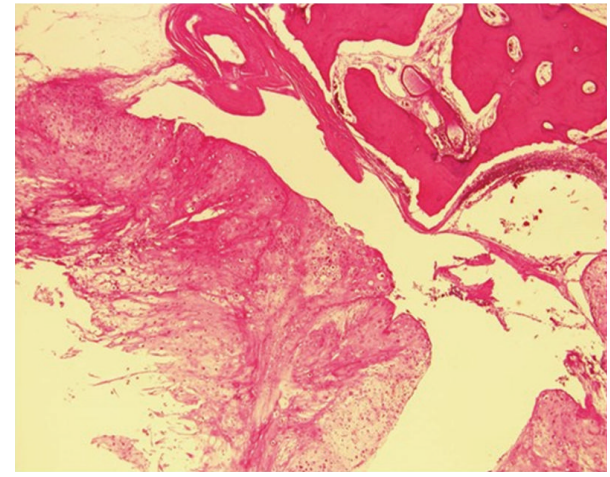

(a)

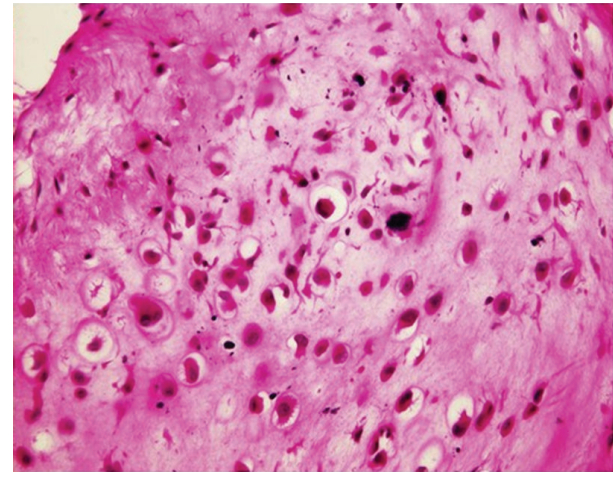

(b)

FIGURE 4: (a) Atypical chondrocytic cells in myxoid or chondroid matrix showing scattered granular calcified materials $(\times 40$, HE staining) and (b) pleomorphism with bizarre appearance of nuclei $(\times 400$, HE staining).

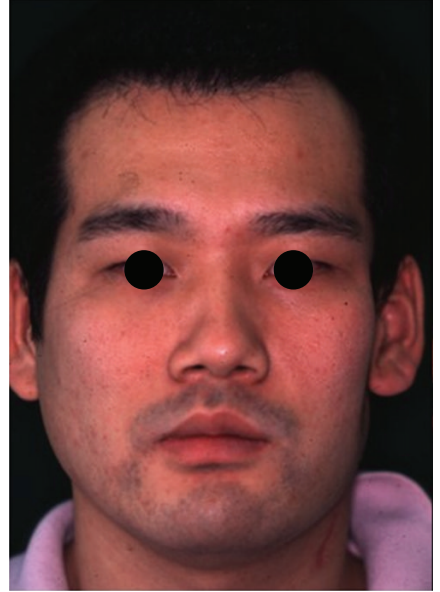

(a)

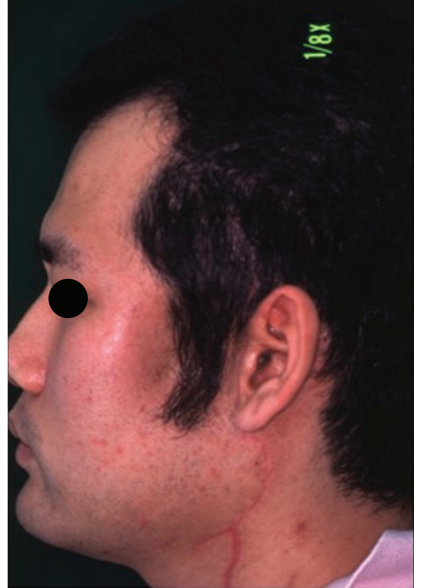

(b)

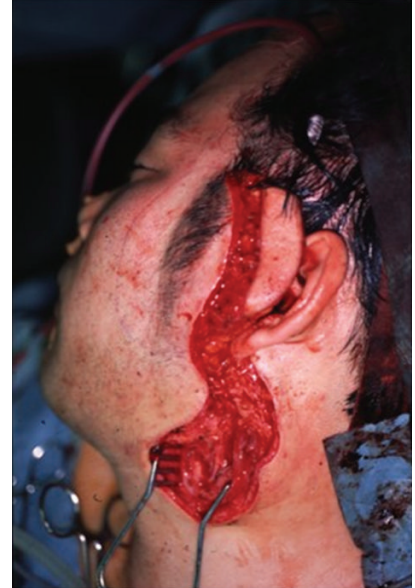

(c)

Figure 5: (a) Frontal view of the patient after tumor resection, (b) lateral view of the patient after tumor resection, and (c) intraoperative view of reconstructive surgery.

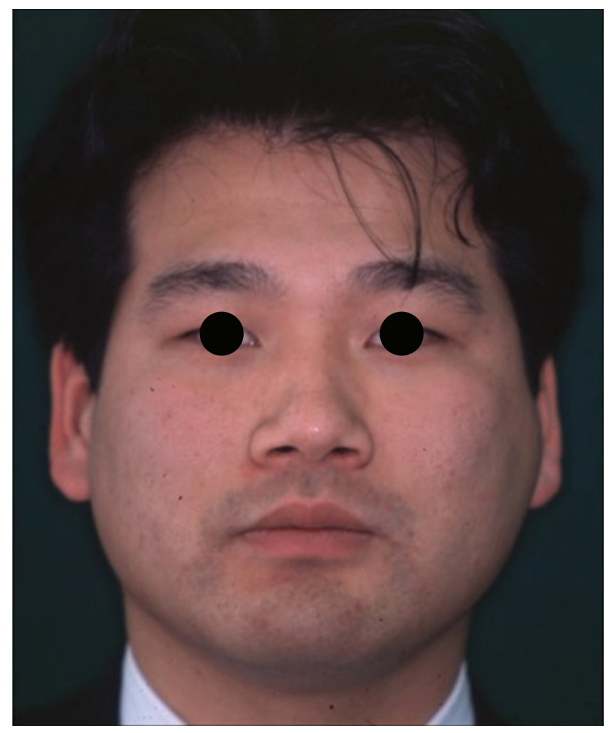

FIGURE 6: Frontal view of the patient one year after reconstructive surgery. 


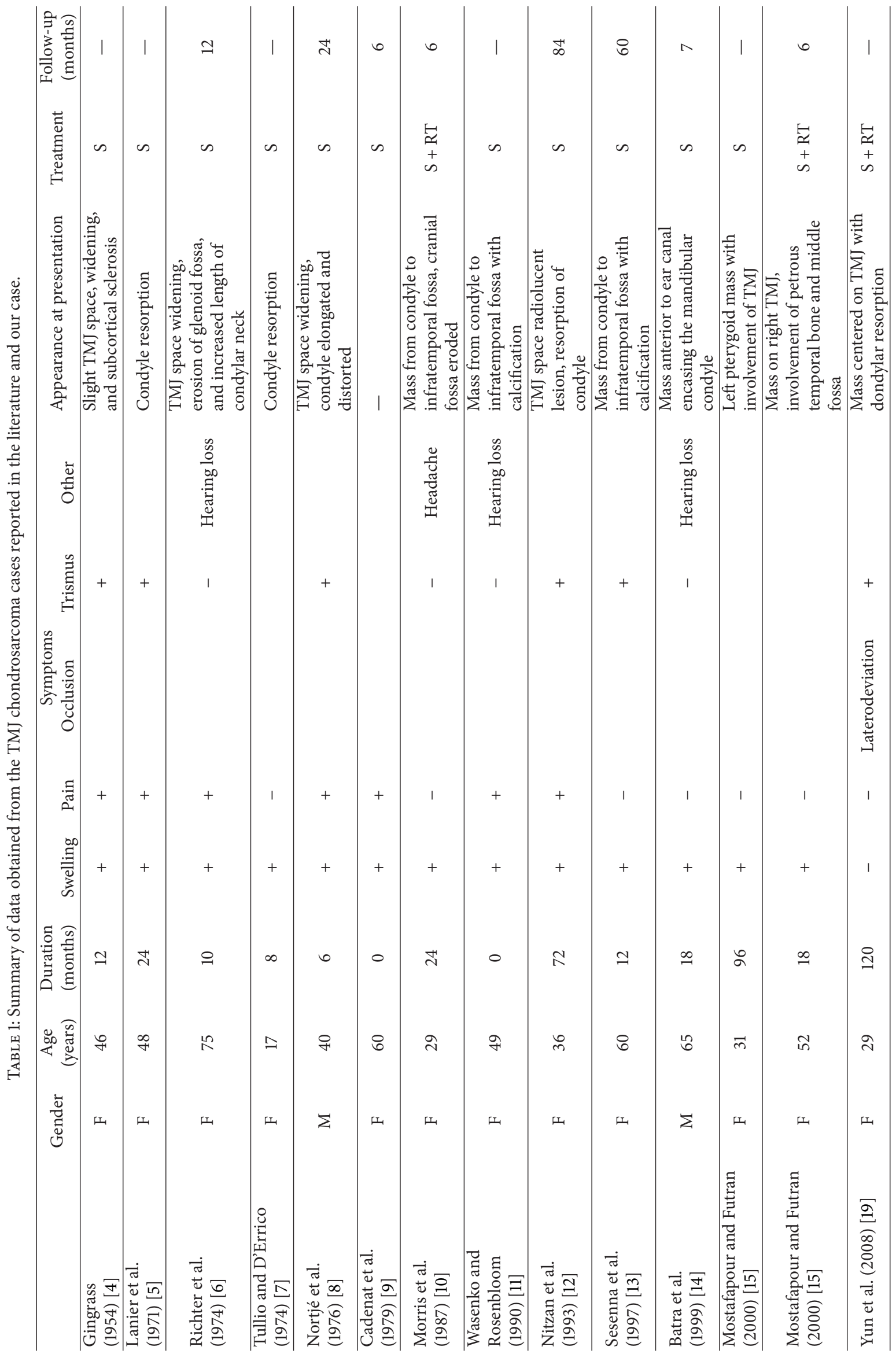




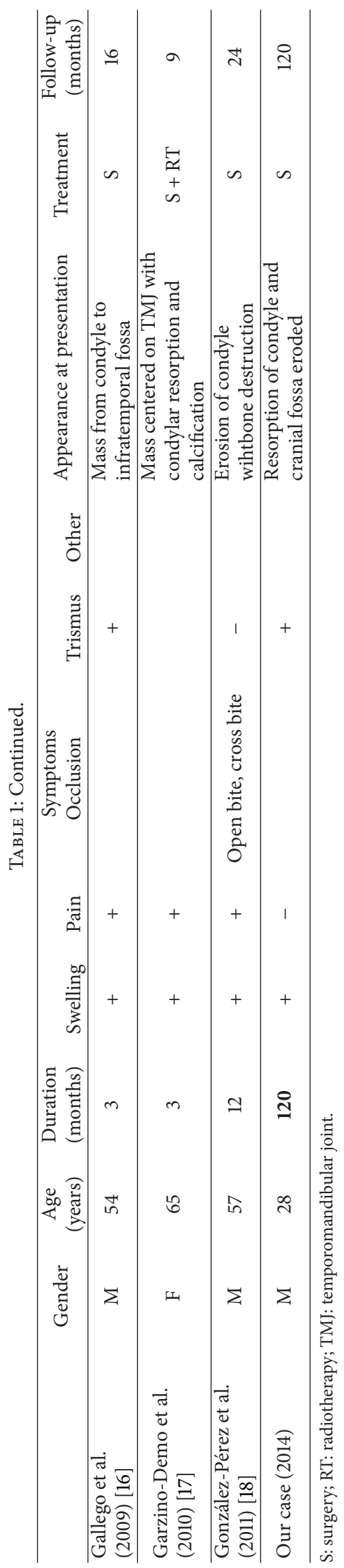


In our case, because of large defect of cranial base, mandible, and soft tissue, we used rectus abdominis-free flap. This flap has a low donor morbidity. This flap served good esthetic outcome in this case.

\section{Conclusion}

Chondrosarcoma in temporomandibular joint is very rare. Tumor was in contact with the dura, but en bloc resection was performed. Face defect was reconstructed by rectus abdominis-free flap. Open biopsy is definite to get final diagnosis. To make differential diagnosis, panorama X-ray, $\mathrm{CT}$, and MRI are effective.

\section{Conflict of Interests}

The authors declare that there is no conflict of interests regarding the publication of this paper.

\section{References}

[1] D. C. Dahlin, Bone Tumors, Charles C. Thomas, Springfield, Ill, USA, 2nd edition, 1967.

[2] L. V. Ackerman, Surgical Pathology, Mosby, St. Louis, Mo, USA, 1968.

[3] K. Saito, K. K. Unni, P. C. Wollan, and B. A. Lund, "Chondrosarcoma of the jaw and facial bones," Cancer, vol. 76, no. 9, pp. 1550-1558, 1995.

[4] R. P. Gingrass, "Chondrosarcoma of the mandibular jointreport of case," Journal of Oral Surgery, vol. 12, no. 1, pp. 61-63, 1954.

[5] V. C. Lanier, L. Rosenfeld, and H. A. Wilkinson, "Chondrosarcoma of the mandible," Southern Medical Journal, vol. 64, no. 6, pp. 711-714, 1971.

[6] K. J. Richter, N. S. Freeman, and C. A. Quick, "Chondrosarcoma of the temporomandibular joint: report of case," Journal of Oral Surgery, vol. 32, no. 10, pp. 777-781, 1974.

[7] G. Tullio and P. D'Errico, "Chondrosarcoma of the mandible. Clinical and histologic considerations," Annali di Stomatologia, vol. 23, no. 10-12, pp. 191-206, 1974.

[8] C. J. Nortjé, A. G. Farman, F. W. Grotepass, and J. A. van Zyl, "Chondrosarcoma of the mandibular condyle. Report of a case with special reference to radiographic features," British Journal of Oral Surgery, vol. 14, no. 2, pp. 101-111, 1976.

[9] H. Cadenat, R. Combelles, G. Fabert, and M. Clouet, "Chondrosarcoma of the condyle," Revue de Stomatologie et de Chirurgie Maxillo-Faciale, vol. 80, no. 1, pp. 20-22, 1979.

[10] M. R. Morris, S. K. Clark, B. A. Porter, and R. J. Delbecq, "Chondrosarcoma of the temporomandibular joint: case report," Head and Neck Surgery, vol. 10, no. 2, pp. 113-117, 1987.

[11] J. J. Wasenko and S. A. Rosenbloom, "Temporomandibular joint chondrosarcoma: CT demonstration," Journal of Computer Assisted Tomography, vol. 14, no. 6, pp. 1002-1003, 1990.

[12] D. W. Nitzan, Y. Marmary, O. Hasson, and J. Elidan, "Chondrosarcoma arising in the temporomandibular joint: a case report and literature review," Journal of Oral and Maxillofacial Surgery, vol. 51, no. 3, pp. 312-315, 1993.

[13] E. Sesenna, A. Tullio, and S. Ferrari, "Chondrosarcoma of the temporomandibular joint: a case report and review of the literature," Journal of Oral and Maxillofacial Surgery, vol. 55, no. 11, pp. 1348-1352, 1997.

[14] P. S. Batra, S. A. Estrem, R. P. Zitsch, R. McDonald, and J. Ditto, "Chondrosarcoma of the temporomandibular joint," Otolaryngology - Head and Neck Surgery, vol. 120, no. 6, pp. 951954, 1999.

[15] S. P. Mostafapour and N. D. Futran, "Tumors and tumorous masses presenting as temporomandibular joint syndrome," Otolaryngology-Head and Neck Surgery, vol. 123, no. 4, pp. 459-464, 2000.

[16] L. Gallego, L. Junquera, M. F. Fresno, and J. C. de Vicente, "Chondrosarcoma of the temporomandibular joint. A case report and review of the literature," Medicina Oral, Patología Oral y Cirugía Bucal, vol. 14, no. 1, pp. E39-E43, 2009.

[17] P. Garzino-Demo, G. Tanteri, P. Boffano et al., "Chondrosarcoma of the temporomandibular joint: a case report and review of the literature," Journal of Oral and Maxillofacial Surgery, vol. 68, no. 8, pp. 2005-2011, 2010.

[18] L. M. González-Pérez, F. Sánchez-Gallego, J. L. Pérez-Ceballos, and D. López-Vaquero, "Temporomandibular joint chondrosarcoma: case report," Journal of Cranio-Maxillofacial Surgery, vol. 39, no. 1, pp. 79-83, 2011.

[19] K.-I. Yun, M.-K. Park, C.-H. Kim, and J.-U. Park, "Chondrosarcomain the mandibular condyle: case report," Journal of the Korean Association of Oral and Maxillofacial Surgeons, vol. 34, no. 1, pp. 95-98, 2008.

[20] S. Murayama, I. Suzuki, M. Nagase et al., "Chondrosarcoma of the mandible. Report of case and a survey of 23 cases in the Japanese literature," Journal of Cranio-Maxillo-Facial Surgery, vol. 16, no. 6, pp. 287-292, 1988.

[21] W. W. Weiss Jr. and J. A. Bennett, "Chondrosarcoma: a rare tumor of the jaws," Journal of Oral and Maxillofacial Surgery, vol. 44, no. 1, pp. 73-79, 1986.

[22] H. L. Evans, A. G. Ayala, and M. M. Romsdahl, "Prognostic factors in chondrosarcoma of bone. A clinicopathologic analysis with emphasis on histologic grading," Cancer, vol. 40, no. 2, pp. 818-831, 1977. 


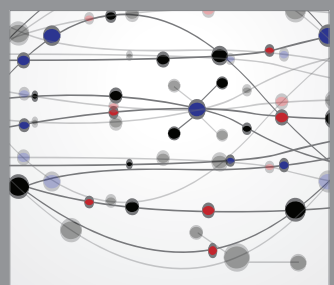

The Scientific World Journal
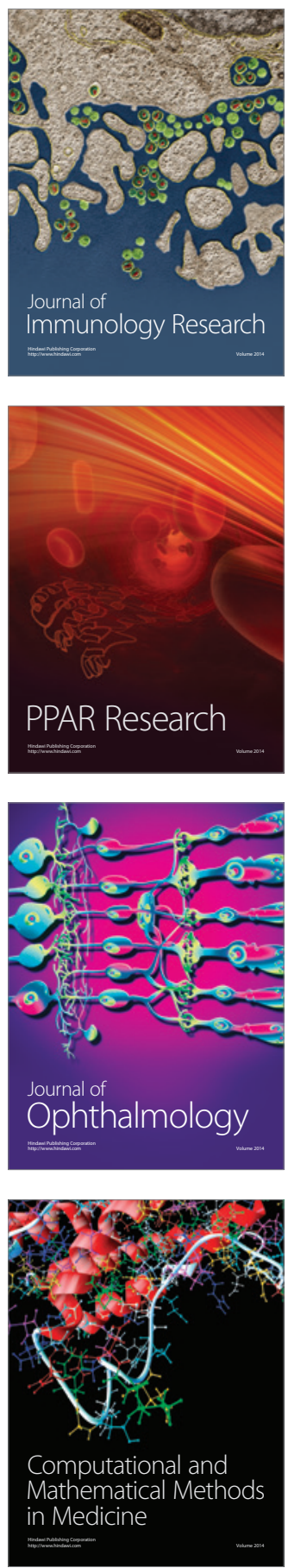

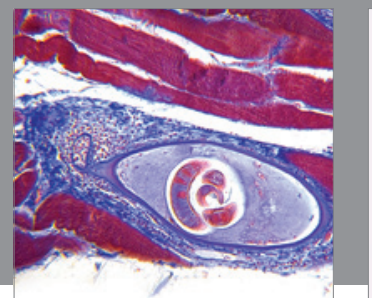

Gastroenterology

Research and Practice
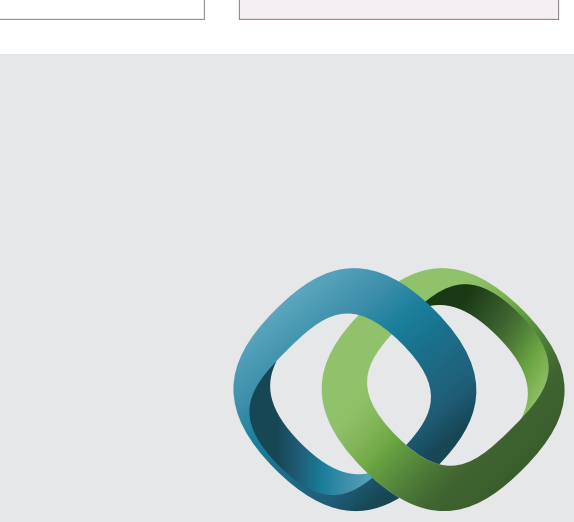

\section{Hindawi}

Submit your manuscripts at

http://www.hindawi.com
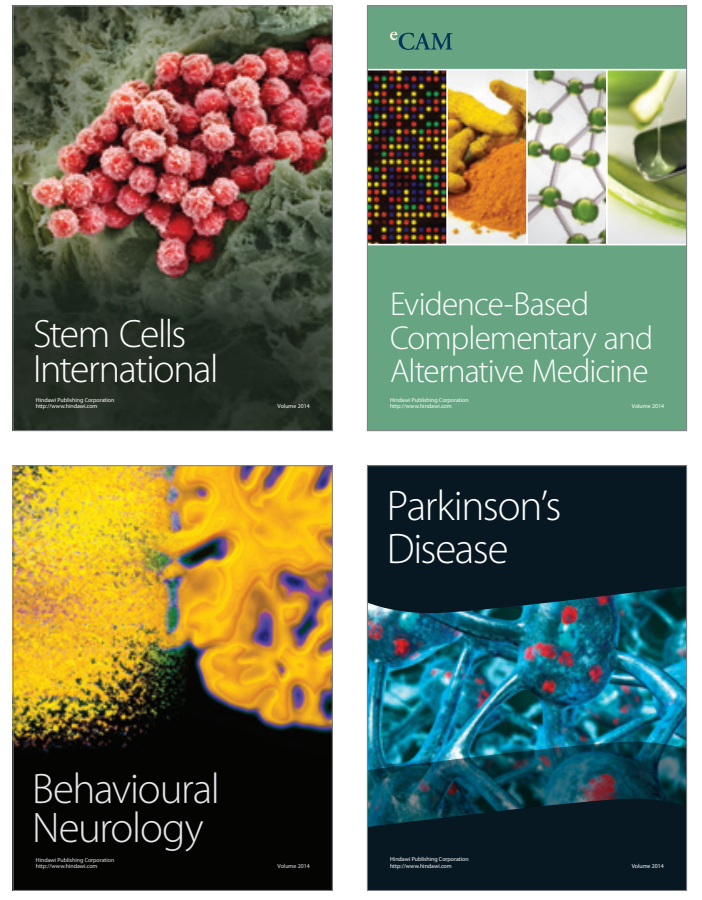
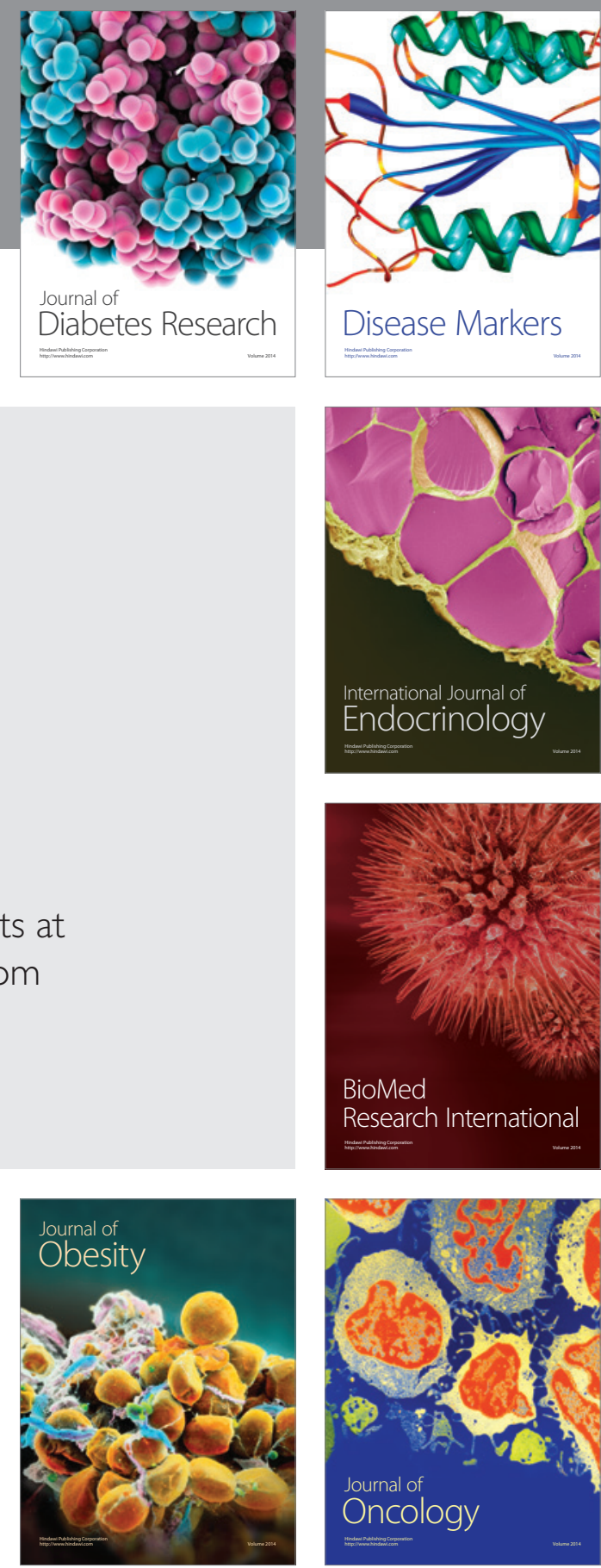

Disease Markers
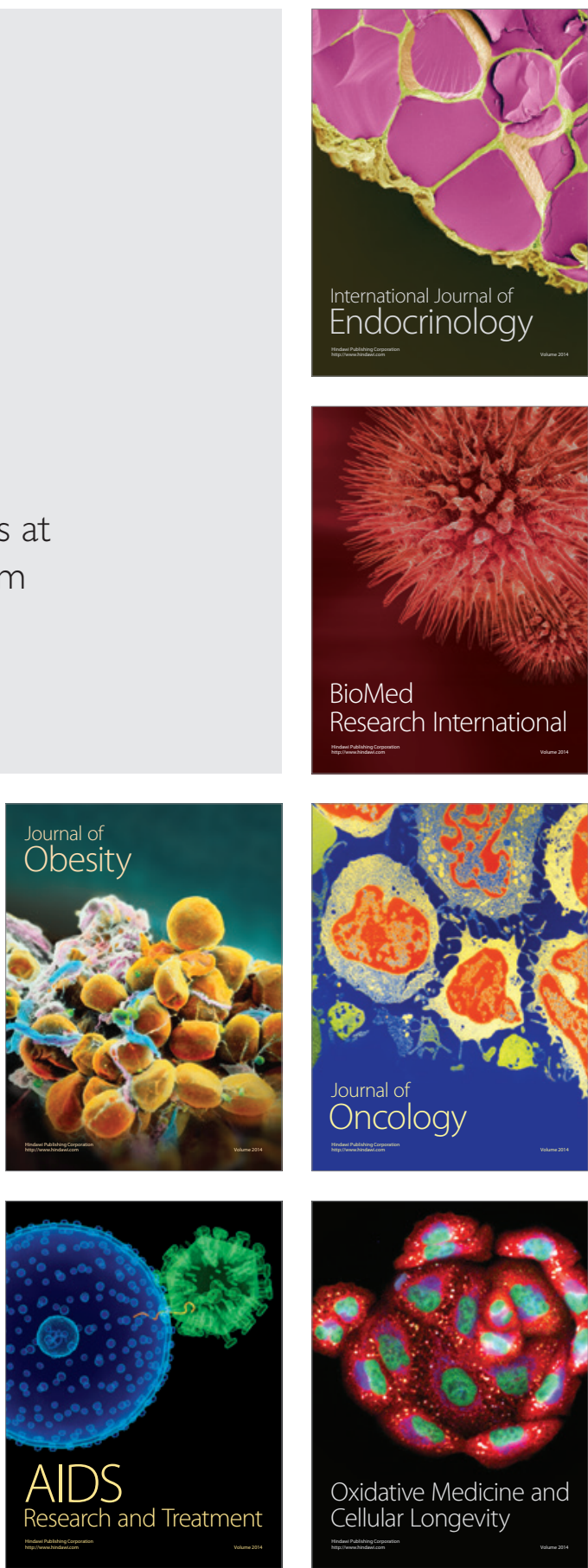